\title{
Does the severity of preoperative anemia or blood transfusion have a stronger impact on long-term survival after cardiac surgery?
}

\author{
Christian von Heymann, MD, DEAA, ${ }^{\mathrm{a}, \mathrm{d}}$ Lutz Kaufner, MD, MSc, ${ }^{\mathrm{a}}$ Michael Sander, MD, ${ }^{\mathrm{a}}$ \\ Claudia Spies, MD, ${ }^{a}$ Karina Schmidt, ${ }^{a}$ Hans Gombotz, MD, ${ }^{c}$ Klaus-Dieter Wernecke, PhD, ${ }^{\mathrm{a}, \mathrm{b}}$ and \\ Felix Balzer, MD, MSc ${ }^{\mathrm{a}}$
}

\begin{abstract}
Background: Preoperative anemia and transfusion are associated with increased morbidity and mortality in cardiac surgery patients. It is unclear which of these factors plays the leading role in poor outcomes after cardiac surgery. The goal of this study was to analyze the influence of anemias of varying severity and intraoperative transfusion on long-term survival, and to characterize their interaction in cardiac surgery patients.
\end{abstract}

Methods: This was an observational cohort study conducted at a German university hospital. All patients undergoing cardiac surgery between 2006 and 2011 were screened for eligibility; duration of follow-up was 3 years. A total of 4494 patients were suitable for analysis; data on long-term survival were available for 3131 of these patients. The main outcome measure was survival at the 3-year follow-up. Length of stay and in-hospital mortality were assessed as secondary outcomes.

Results: Multivariate Cox regression analyses indicated that both the severity of preoperative anemia (mild anemia: hazard ratio [HR], 1.441; 95\% confidence interval [CI], 1.201-1.728; severe anemia: HR, 1.805; 95\% CI, 1.336-2.440) and intraoperative transfusion (HR, 1.340; 95\% CI, 1.109-1.620) were associated with decreased long-term survival. Long-term survival was worse in anemic patients who received an intraoperative transfusion compared with those who did not receive an intraoperative transfusion.

Conclusions: Both preoperative anemia and transfusion are by themselves and in combination associated with decreased long-term survival. When anemic patients require transfusion, our results provide evidence that the risk of death after cardiac surgery may depend to a considerable extent on the severity of preoperative anemia. (J Thorac Cardiovasc Surg 2016;152:1412-20)

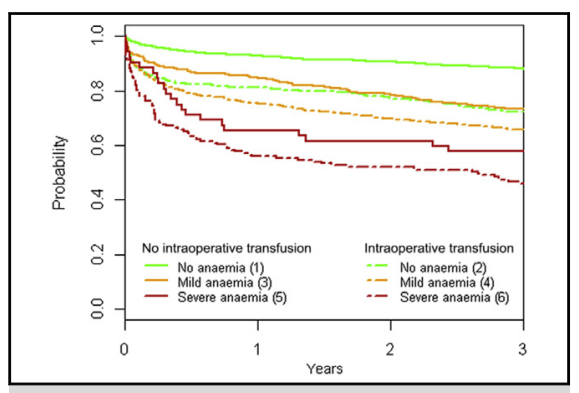

Kaplan-Meier curves depicting long-term survival of patients depending on anemia and/or transfusion.

\section{Central Message}

Preoperative anemia, dependent mainly on its severity, and transfusion seem to have comparable odds for decreased long-term survival.

\section{Perspective}

Preoperative anemia and transfusion, by themselves and in combination, are associated with decreased survival in cardiac surgery patients. When patients require transfusion, our data suggest that mortality depends largely on the severity of anemia.

See Editorial Commentary page 1421.

\footnotetext{
From the ${ }^{\mathrm{a}}$ Department of Anesthesiology and Intensive Care Medicine, Charité-Universitätsmedizin Berlin; ${ }^{\mathrm{b}} \mathrm{SOSTANA} \mathrm{GmbH}$; ${ }^{\mathrm{c}}$ Department of Anesthesiology and Intensive Care, General Hospital Linz, Linz, Austria; and ${ }^{\mathrm{d} D e p a r t m e n t ~ o f ~ A n e s t h e s i o l o g y, ~ I n t e n s i v e ~ C a r e ~ M e d i c i n e, ~ E m e r g e n c y ~ M e d i c i n e ~}$ and Pain Therapy, Vivantes Klinikum im Friedrichshain, Berlin, Germany.

The study was supported by an institutional grant from Charité-Universitätsmedizin Berlin. No external funds were obtained.

C.v.H. and L.K. contributed equally to this work.

Received for publication Aug 19, 2015; revisions received May 29, 2016; accepted for publication June 9, 2016; available ahead of print July 21, 2016.

Address for reprints: Christian von Heymann, MD, DEAA, Department of Anesthesiology, Intensive Care Medicine and Pain Therapy, Vivantes Klinikum im Friedrichshain, Landsberger Allee 49, 10249 Berlin, Germany (E-mail: christian.heymann@vivantes.de).

$0022-5223 / \$ 36.00$

Copyright (c) 2016 by The American Association for Thoracic Surgery

http://dx.doi.org/10.1016/j.jtcvs.2016.06.010
}

Patients undergoing cardiac surgery with preoperative anemia are at high risk for early 30-day mortality. ${ }^{1}$ In-hospital mortality in cardiac surgery patients has been reported to be $7.7 \%$ for mild anemia (hemoglobin $[\mathrm{Hb}], 11.0-12.9 \mathrm{~g} / \mathrm{dL}$ in men and 11.0-11.9 $\mathrm{g} / \mathrm{dL}$ in women) and $15.7 \%$ for moderate and severe anemia $(\mathrm{Hb}<11.0 \mathrm{~g} / \mathrm{dL}){ }^{2}$ A significant increase in late mortality $>30$ days after cardiac

Scanning this QR code will take you to the article title page. 


$$
\begin{aligned}
& \text { Abbreviations and Acronyms } \\
& \text { ACEF }=\text { age, creatinine, and ejection fraction } \\
& \text { BMI }=\text { body mass index } \\
& \text { CABG }=\text { coronary artery bypass grafting } \\
& \text { CI }=\text { confidence interval } \\
& \text { COPD }=\text { chronic obstructive pulmonary disease } \\
& \text { CPB }=\text { cardiopulmonary bypass } \\
& \mathrm{Hb}=\text { hemoglobin } \\
& \text { HR }=\text { hazard ratio } \\
& \text { ICU }=\text { intensive care unit } \\
& \text { IQR }=\text { interquartile range } \\
& \text { LVEF }=\text { left ventricular ejection fraction } \\
& \text { PDMS }=\text { patient data management system } \\
& \text { RBC }=\text { red blood cell } \\
& \text { WHO }=\text { World Health Organization }
\end{aligned}
$$

surgery has been reported for patients with $\mathrm{Hb}<12 \mathrm{~g} / \mathrm{dL}^{3,4}$; however, the impact of severe preoperative anemia $(\mathrm{Hb}$ $<10 \mathrm{~g} / \mathrm{dL}$ ) on short- and long-term survival after cardiac surgery remains unclear.

Preoperative and intraoperative strategies to treat anemia and avoid transfusion are recommended by national German and international guidelines, ${ }^{5,6}$ yet patients with preoperative anemia undergoing cardiac surgery are more likely to receive a transfusion than patients without preoperative anemia. ${ }^{7,8}$ Even though the most widely used treatment for preoperative anemia is transfusion of allogeneic packed red blood cells (RBCs), this treatment is controversial, given that blood transfusion has been associated with adverse outcomes after cardiac surgery. Receipt of transfusion has been identified as an important risk factor for 30-day and long-term all-cause mortality, ${ }^{9-11}$ myocardial infarction, ${ }^{9}$ and acute renal failure. ${ }^{12}$ Moreover, treating anemia with transfusion is associated with prolonged stays in the intensive care unit (ICU) and the hospital, ${ }^{10}$ as well as with significantly greater short-term mortality $(<30$ days) in patients with preoperative anemia compared with those without preoperative anemia ${ }^{13}$; however, this association was shown only for mild anemia and short-term survival.

For that reason, the primary purpose of this work was to assess the degree to which the severity of anemia impacts long-term mortality after cardiac surgery. Furthermore, given that both preoperative anemia and its treatment (blood transfusion) impair outcomes after cardiac surgery and may confound the assessment of each risk factor, the secondary purpose was to weigh the risk of anemia and blood transfusion for 3-year survival after cardiac surgery.

\section{METHODS}

\section{Data Source}

This observational cohort study was conducted at Charité-University Hospital in Berlin, Germany. After approval from the Federal Data
Protection Officer and the hospital's Ethics Commission (Ethikkommission der Charité-Universitätsmedizin Berlin; reference no. EA1/034/13), routine clinical data from all patients undergoing cardiac surgery between 2006 and 2011 were extracted from the 2 electronic patient data management systems (PDMSs) at our hospital (COPRA System; Sasbachwalden, Germany and SAP AG; Walldorf, Germany). Owing to its retrospective character, the need for informed patient consent was waived by the Ethics Commission. The time frame for this analysis was chosen to generate a representative substantial study population with minimal effects of changes in cardiac surgery procedures over time.

\section{Patient Population}

We included all patients aged 18 or older who underwent cardiac surgery during the study period. Patients without preoperative assessment of $\mathrm{Hb}$ or electronic documentation of intraoperative transfusion were excluded.

Patient age, sex, and body mass index (BMI); preexisting medical conditions; type and duration of surgery, with duration of cardiopulmonary bypass (CPB) as a marker of its complexity; and preoperative risk $^{14}$ and postoperative ICU admission scores (ie, APACHE II [Acute Physiology and Chronic Health Evaluation II] ${ }^{15}$ and TISS-28 [Therapeutic Intervention Scoring System 28$]^{16}$ ) were used to characterize the study population and to identify possible confounders. Preexisting medical conditions were derived from International Classification of Diseases, Tenth Revision coded diagnoses available from the PDMS. Renal dysfunction was defined as a preoperative serum creatinine level $>1.7 \mathrm{mg} / \mathrm{dL}$.

\section{Definitions and End Points}

Cardiac surgery. Cardiac surgery was defined as any documented procedure for a coronary artery bypass grafting (CABG), valve surgery or a combination of the 2 , including both elective and emergency procedures. CPB and anesthesia management were performed according to the department's standard operating procedures. ${ }^{17}$ After chest closure, the patient was transferred to the ICU while intubated and mechanically ventilated. Patients were extubated when hemodynamic stability was achieved (ie, heart rate of $80-100 \mathrm{bpm}$, mean arterial pressure of 65-85 $\mathrm{mm} \mathrm{Hg}$, central venous pressure of $8-12 \mathrm{~mm} \mathrm{Hg}$ (at a positive end-expiratory pressure of $5 \mathrm{~cm} \mathrm{H}_{2} \mathrm{O}$ ), pulmonary artery occlusion pressure of $12-15 \mathrm{~mm} \mathrm{Hg}$, cardiac index of $>2.5 \mathrm{~L} / \mathrm{min} / \mathrm{m}^{2}$, stroke volume index of $>30 \mathrm{~mL} / \mathrm{m}^{2}$, mixed venous oxygen saturation of $>65$ ), chest tube drainage was negligible $(<100 \mathrm{~mL} / \mathrm{h}$ ) and lung function was sufficient (oxygen saturation in arterial blood $\geq 95 \%$, with a fraction of inspired oxygen value $\leq 35 \%) .{ }^{18}$ Hemodynamic optimization was maintained continuously according to German guidelines. ${ }^{19}$

\section{Severity of Preoperative Anemia}

Following the definition of the World Health Organization (WHO), female patients with a preoperative $\mathrm{Hb}$ level $<12 \mathrm{~g} / \mathrm{dL}$ and male patients with a preoperative $\mathrm{Hb}<13 \mathrm{~g} / \mathrm{dL}$ were classified as anemic. ${ }^{20}$ Further subclassification was done for mild anemia (females, $\mathrm{Hb} 10-12 \mathrm{~g} / \mathrm{dL}$; males, $\mathrm{Hb} 10-13 \mathrm{~g} / \mathrm{dL}$ ) and severe anemia (females and males, $\mathrm{Hb}$ $\leq 10 \mathrm{~g} / \mathrm{dL}$ ). Grouping was based on the last available $\mathrm{Hb}$ value measured before surgery.

\section{Intraoperative Transfusion}

Intraoperative transfusion was administered according to institutional standard operating procedures, ${ }^{17,18}$ which are based on national guidelines. ${ }^{6}$ In these guidelines, an $\mathrm{Hb}$ of $6 \mathrm{~g} / \mathrm{dL}(3.7 \mathrm{mmol} / \mathrm{L})$ is defined 
as a threshold for RBC transfusion. In patients with a moderately reduced $\mathrm{Hb}$ of 6 to $8 \mathrm{~g} / \mathrm{dL}(3.7$ to $5.0 \mathrm{mmol} / \mathrm{L})$, recommendations depend on individual risk factors and compensation capabilities. In the absence of respective preexisting medical conditions, such as coronary heart disease, heart failure, or cerebrovascular insufficiency, RBC transfusions are not recommended. In contrast, if these conditions are present or if there are signs of anemic hypoxia (eg, tachycardia, hypotension, pathological electrocardiogram), a transfusion should be administered. Likewise, transfusion is recommended in patients who present with both an $\mathrm{Hb}$ of 8 to $10 \mathrm{~g} / \mathrm{dL}$ ( 5.0 to $6.2 \mathrm{mmol} / \mathrm{L}$ ) and signs of anemic hypoxia. On the other end, patients with an $\mathrm{Hb}>10 \mathrm{~g} / \mathrm{dL}(6.2 \mathrm{mmol} / \mathrm{L})$ should not be considered for hemotherapy.

The patients included in this study did not participate in an autologous blood donation program. We assessed the number of RBC units administered during the duration of surgery. Taking into account that even transfusion of 1 or 2 RBC units may have an impact on outcome,${ }^{21}$ transfusion was considered a dichotomous variable in statistical analysis, thus not accounting for the number of transfused units. Patients who received a hemostatic agent, such as fresh-frozen plasma or thrombocytes, but no RBCs, were not included in the group of transfused patients.

\section{Outcomes}

The primary study endpoint was long-term survival. For this purpose, we defined a subpopulation of patients with an observation time of 3 years after surgery. This means that events (death) were registered only within 3 years after surgery, patients who were lost to follow-up (within 3 years) were censored, and patients who survived for $>3$ years were censored with the end of observation period ( 3 years after surgery). Data on long-term survival were acquired by consulting the local authorities in Berlin, Germany, after clearance from the Federal Data Safety Officer. In-hospital mortality, length of stay in the ICU, and length of stay in the hospital were defined as secondary endpoints.

\section{Interaction of Severity of Preoperative Anemia and Intraoperative Transfusion}

To account for interactions of preoperative anemia and $\mathrm{RBC}$ transfusion, an interaction term was defined out of both variables, resulting in 6 combinations of preoperative anemia of different severity and transfusion: no anemia/no transfusion, no anemia/transfusion, mild anemia/no transfusion, mild anemia/transfusion, severe anemia/no transfusion, and severe anemia/transfusion.

\section{Statistical Analyses}

Descriptive analyses and statistical testing were performed using $\mathrm{R}$ 3.0.1. ${ }^{22}$ We considered a $P$ value $<.05$ as significant. When normal distribution was ruled out using the Kolmogorov-Smirnov test, results are given as median and interquartile range (IQR); otherwise, they are given as mean \pm standard deviation. Qualitative observations are characterized by frequency, in percentage. Statistical significance among groups was univariately analyzed using the exact nonparametric Kruskal-Wallis test and (pairwise) with the exact Mann-Whitney $U$ test. The exact $\chi^{2}$ test was used for qualitative data. Survival was analyzed using Kaplan-Meier estimations and tested using the log-rank test between groups.

To accommodate a multivariate design, survival analyses were carried out using Cox regression analysis on the following preoperative variables: age; sex; $\mathrm{BMI}$; type of surgery; duration of $\mathrm{CPB}$; priority of surgery; age, serum creatinine level, and ejection fraction (ACEF) score $^{14}$; chronic obstructive pulmonary disease (COPD); coronary artery disease; diabetes mellitus; atrial fibrillation; peripheral vascular

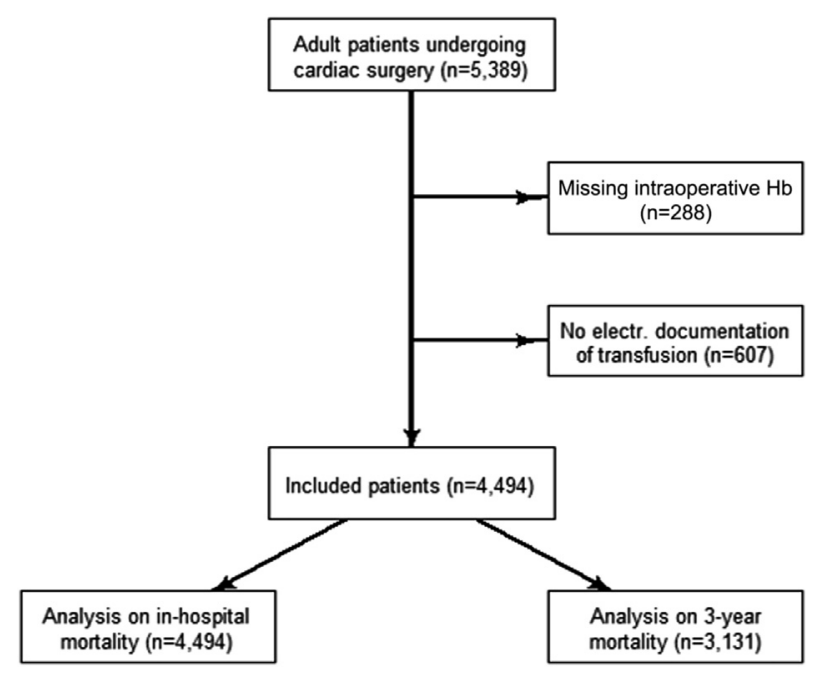

FIGURE 1. CONSORT diagram of the study. $H b$, Hemoglobin.

disease; left ventricular ejection fraction (LVEF) $<35 \%$; and preoperative renal insufficiency, reflected by preoperative serum creatinine $>1.7 \mathrm{mg} / \mathrm{dL}$. In addition, preoperative anemia and intraoperative transfusion were included as categorical variables in the analysis as potential confounders.

We investigated the association between the severity of preoperative anemia and intraoperative transfusion by repeating the foregoing regression model and replacing the 2 variables by an interaction term combining all combinations (see above). Furthermore, specific hazard ratios (HRs) for all combinations of anemia and transfusion were calculated to quantify their impact on survival. All tests are presented as explorative analyses, because no adjustments for multiple testing were made. The proportional hazards assumption was checked. Grambsch tests yielded a violation of the assumption, but log-minus-log plots revealed that the violation refers to the beginning of the observation period, in line with the widely acknowledged observation that deaths within a few months after surgery and deaths beyond 1 year after surgery are attributed to different causes and have different risk factors.

\section{RESULTS \\ Patient Characteristics}

Over the 6-year observation period, 5389 patients undergoing cardiac surgery were screened for eligibility (Figure 1). We excluded 288 patients because of missing preoperative $\mathrm{Hb}$ values, and another 607 patients for whom information on intraoperative transfusion was not available. Basic characteristics of the 4494 patients included in the analysis are presented in Table 1. Data on long-term survival were available for 3547 patients, of whom 416 were excluded from analyses of long-term outcome, because the observation period was shorter than the previously defined interval of 3 years. Patients with anemia presented less frequently with coronary heart disease, but more often with COPD, diabetes mellitus, peripheral vascular disease, atrial fibrillation, an LVEF $<35 \%$, and preoperative renal dysfunction $(P<.05$ for all) (Table 1). 
TABLE 1. Patient characteristics

\begin{tabular}{|c|c|c|c|c|}
\hline Characteristic & $\begin{array}{c}\text { All } \\
(n=4494) \\
\end{array}$ & $\begin{array}{l}\text { No anemia } \\
(\mathrm{n}=\mathbf{2 8 7 4})\end{array}$ & $\begin{array}{c}\text { Anemia } \\
(\mathrm{n}=1620)\end{array}$ & $P$ value \\
\hline \multicolumn{5}{|l|}{ Basic data } \\
\hline Age, y, median (IQR) & $69.0(61.0-75.0)$ & $68.0(60.0-74.0)$ & $70.0(64.0-76.0)$ & $<.001$ \\
\hline Female sex, n $(\%)$ & $1279(28.5)$ & $775(27.0)$ & $504(31.1)$ & .003 \\
\hline Body mass index, median (IQR) & $26.9(24.3-30.1)$ & $27.3(24.6-30.4)$ & $26.1(23.7-29.7)$ & $<.001$ \\
\hline \multicolumn{5}{|l|}{ Surgery } \\
\hline Type of surgery, n (\%) & & & & $<.001$ \\
\hline Coronary artery bypass grafting & $2503(55.7)$ & $1721(59.9)$ & $782(48.3)$ & \\
\hline Valves & $1393(31.0)$ & $807(28.1)$ & $586(36.2)$ & \\
\hline Both & $598(13.3)$ & $346(12.0)$ & $252(15.6)$ & \\
\hline Duration of anesthesia, min, median (IQR) & $285(235-335)$ & $285(235-330)$ & $290(240-340)$ & .019 \\
\hline Duration of surgery, min, median (IQR) & $195(155-240)$ & $195(155-240)$ & $195(160-242)$ & .035 \\
\hline Time on cardiopulmonary bypass, h, median (IQR) & $86.0(64.0-114)$ & $84.0(63.0-111)$ & $91.0(67.0-121)$ & $<.001$ \\
\hline Priority of surgery, $\mathrm{n}(\%)$ & & & & $<.001$ \\
\hline Elective & $3040(78.3)$ & 2027 (80.4) & $1013(74.3)$ & \\
\hline Urgent & $375(9.65)$ & $206(8.17)$ & $169(12.4)$ & \\
\hline Emergency & $469(12.1)$ & $287(11.4)$ & $182(13.3)$ & \\
\hline Age, creatinine, and ejection fraction score, median (IQR) & $1.30(1.12-1.63)$ & $1.24(1.10-1.50)$ & $1.42(1.22-1.97)$ & $<.001$ \\
\hline Red blood cell transfusion (patients \%), n (\%) & $1247(27.7)$ & $441(15.3)$ & $806(49.8)$ & $<.001$ \\
\hline Red blood cell transfusion, units, median (IQR) & $2.00(1.00-2.00)$ & $2.00(1.00-2.00)$ & $2.00(1.00-2.00)$ & $<.001$ \\
\hline \multicolumn{5}{|l|}{ Scores on postoperative intensive care unit admission, median (IQR) } \\
\hline APACHE II & $18.0(14.0-24.0)$ & $17.0(14.0-22.0)$ & $20.0(16.0-25.0)$ & $<.001$ \\
\hline TISS28 & $36.0(33.0-40.0)$ & $36.0(33.0-40.0)$ & $36.0(32.0-41.0)$ & .734 \\
\hline \multicolumn{5}{|l|}{ Preexisting medical conditions, $\mathrm{n}(\%)$} \\
\hline Coronary heart disease & $3450(76.8)$ & $2239(77.9)$ & $1211(74.8)$ & .018 \\
\hline Chronic obstructive pulmonary disease & $791(17.6)$ & $451(15.7)$ & $340(21.0)$ & $<.001$ \\
\hline Diabetes mellitus & $1863(41.5)$ & $1070(37.2)$ & $793(49.0)$ & $<.001$ \\
\hline Hyperlipidemia & $1277(28.4)$ & $838(29.2)$ & $439(27.1)$ & .151 \\
\hline Peripheral vascular disease & $811(18.0)$ & $431(15.0)$ & $380(23.5)$ & $<.001$ \\
\hline Atrial fibrillation & $1346(30.0)$ & $722(25.1)$ & $624(38.5)$ & $<.001$ \\
\hline Left ventricular ejection fraction $<35$ & $426(12.1)$ & $248(10.6)$ & $178(15.0)$ & $<.001$ \\
\hline Preoperative serum creatinine $>1.7 \mathrm{mg} / \mathrm{dL}^{*}$ & $421(9.40)$ & $115(4.01)$ & $306(19.0)$ & $<.001$ \\
\hline
\end{tabular}

Anemia: Females, $\mathrm{Hb}<12 \mathrm{~g} / \mathrm{dL}$; males, $\mathrm{Hb}<13 \mathrm{~g} / \mathrm{dL}$. IQR, Interquartile range; APACHE II, Acute Physiology and Chronic Health Evaluation II; TISS-28, Therapeutic Intervention Scoring System 28. *Conversion factor to SI units, 76.25.

The severity of anemia and other patient characteristics is presented in Table 2. A total of 1274 patients $(28 \%)$ presented with mild preoperative anemia, and 346 patients $(8 \%)$ presented with severe preoperative anemia. Compared with nonanemic patients, the group with mild or severe anemia had a slightly higher median age $(P<.001)$ with a higher percentage of women $(P=.003)$ (Table 2$)$. Compared with the mild anemia group, the severe anemia group had more women $(P<.001)$ and more patients who underwent valve surgery $(P<.001)$. Patients with severe anemia had a longer time on CPB $(P<.001)$ and a higher priority of surgery $(P<.001)$. Moreover, severely anemic patients required RBC transfusions more frequently (median, 1 [IQR, 0 to 2] vs 0 [IQR, 0 to 2]; $P<.001$ ). In terms of preexisting medical conditions, patients with severe anemia had a lower incidence of coronary artery disease, but higher rates of diabetes mellitus, atrial fibrillation, and preoperative renal dysfunction $(P<.05$ for all $)($ Table 2$)$.

\section{Outcomes}

Three-year mortality was $15.0 \%$ in nonanemic patients, $30.8 \%$ in mildly anemic patients, and $51.2 \%$ in severely anemic patients $(P<.001)$. In-hospital survival showed a similar distribution, with mortality rates of $3.7 \%$ in nonanemic patients, $8.6 \%$ in mildly anemic patients, and $15.0 \%$ in severely anemic patients $(P<.001)$. On average, nonanemic patients stayed 4 (IQR, 3 to 7) days in the ICU, compared with 6 (IQR, 4 to 11 days) for mildly anemic patients $(P<.001)$ and 10.5 (IQR, 5 to 25$)$ days for severely anemic patients $(P<.001)$. The median length of hospital stay was 12 (IQR, 8 to 17 ) days for nonanemic patients, compared with 15 (IQR, 10 to 25 ) days for mildly anemic patients $(P<.001)$ and 21 (IQR, 13 to 39$)$ days for severely anemic patients $(P<.001)$ (Table 2$)$. 
TABLE 2. Patient characteristics and outcomes depending on the severity of preoperative anemia compared with no anemia

\begin{tabular}{|c|c|c|c|c|c|c|}
\hline Characteristic & $\begin{array}{l}\text { No anemia } \\
(\mathrm{n}=\mathbf{2 8 7 4})\end{array}$ & $\begin{array}{l}\text { Mild anemia } \\
(n=1274)\end{array}$ & $\begin{array}{l}\text { Severe anemia } \\
\quad(\mathrm{n}=\mathbf{3 4 6})\end{array}$ & $\begin{array}{c}P \text { value, } \\
\text { NA vs MA }\end{array}$ & $\begin{array}{c}P \text { value, } \\
\text { NA vs SA }\end{array}$ & $\begin{array}{r}P \text { value, } \\
\text { MA vs } S A\end{array}$ \\
\hline \multicolumn{7}{|l|}{ Basic data } \\
\hline Age, y, median (IQR) & $68.0(60.0-74.0)$ & $71.0(64.0-76.0)$ & $70.0(64.0-76.0)$ & $<.001$ & $<.001$ & .244 \\
\hline Female sex, n (\%) & $775(27.0)$ & $370(29.0)$ & $134(38.7)$ & .179 & $<.001$ & .001 \\
\hline Body mass index, median (IQR) & $27.3(24.6-30.4)$ & $26.0(23.7-29.7)$ & $26.8(23.8-30.5)$ & $<.001$ & .126 & .126 \\
\hline \multicolumn{7}{|l|}{ Surgery } \\
\hline Type of surgery, n (\%) & & & & $<.001$ & $<.001$ & $<.001$ \\
\hline Coronary artery bypass grafting & $1721(59.9)$ & $658(51.6)$ & $124(35.8)$ & & & \\
\hline Valves & $807(28.1)$ & $421(33.0)$ & $165(47.7)$ & & & \\
\hline Coronary artery bypass grafting and valves & $346(12.0)$ & $195(15.3)$ & $57(16.5)$ & & & \\
\hline Duration of anesthesia, min, median (IQR) & $285(235-330)$ & $290(245-340)$ & $290(235-340)$ & .100 & .262 & .857 \\
\hline Duration of surgery, min, median (IQR) & $195(155-240)$ & $195(160-240)$ & $200(155-250)$ & .154 & .154 & .503 \\
\hline Time on cardiopulmonary bypass, $\mathrm{h}$, median (IQR) & $84.0(63.0-111)$ & $89.0(66.0-118)$ & $96.0(68.0-128)$ & $<.001$ & $<.001$ & .015 \\
\hline Priority of surgery, n $(\%)$ & & & & .034 & $<.001$ & $<.001$ \\
\hline Elective & $2027(80.4)$ & $836(77.2)$ & $177(63.0)$ & & & \\
\hline Urgent & $206(8.17)$ & $116(10.7)$ & $53(18.9)$ & & & \\
\hline Emergency & $287(11.4)$ & $131(12.1)$ & $51(18.1)$ & & & \\
\hline $\begin{array}{l}\text { Age, creatinine, and ejection fraction score, } \\
\text { median (IQR) }\end{array}$ & $1.24(1.10-1.50)$ & $1.42(1.21-1.92)$ & $1.45(1.22-2.20)$ & $<.001$ & $<.001$ & .077 \\
\hline Red blood cell transfusion (patients \%), n (\%) & $441(15.3)$ & $579(45.4)$ & $227(65.6)$ & $<.001$ & $<.001$ & $<.001$ \\
\hline Red blood cell transfusion, units, median (IQR) & $2.00(1.00-2.00)$ & $2.00(1.00-2.00)$ & $2.00(1.00-3.00)$ & .007 & $<.001$ & .067 \\
\hline \multicolumn{7}{|c|}{ Scores on postoperative intensive care unit admission, median (IQR) } \\
\hline APACHE II & $17.0(14.0-22.0)$ & $19.0(16.0-25.0)$ & $21.0(16.0-25.8)$ & $<.001$ & $<.001$ & .237 \\
\hline TISS28 & $36.0(33.0-40.0)$ & $36.0(33.0-40.0)$ & $36.0(32.0-42.0)$ & .800 & .239 & .239 \\
\hline \multicolumn{7}{|l|}{ Preexisting medical conditions, $\mathrm{n}(\%)$} \\
\hline Coronary artery disease & $2239(77.9)$ & $983(77.2)$ & $228(65.9)$ & .622 & $<.001$ & $<.001$ \\
\hline Chronic obstructive pulmonary disease & $451(15.7)$ & $264(20.7)$ & $76(22.0)$ & $<.001$ & .006 & .668 \\
\hline Diabetes mellitus & $1070(37.2)$ & $594(46.6)$ & $199(57.5)$ & $<.001$ & $<.001$ & $<.001$ \\
\hline Hyperlipidemia & $838(29.2)$ & $361(28.3)$ & $78(22.5)$ & .616 & .036 & .056 \\
\hline Peripheral vascular disease & $431(15.0)$ & $303(23.8)$ & $77(22.3)$ & $<.001$ & .001 & .600 \\
\hline Atrial fibrillation & $722(25.1)$ & $465(36.5)$ & $159(46.0)$ & $<.001$ & $<.001$ & .002 \\
\hline Left ventricular ejection fraction $<35$ & $248(10.6)$ & $142(14.7)$ & $36(16.5)$ & .004 & .017 & .559 \\
\hline Preoperative serum creatinine $>1.7 \mathrm{mg} / \mathrm{dL}^{*}$ & $115(4.01)$ & $198(15.6)$ & $108(31.4)$ & $<.001$ & $<.001$ & $<.001$ \\
\hline \multicolumn{7}{|l|}{ Outcomes } \\
\hline Mortality, in-hospital, n (\%) & $107(3.72)$ & $109(8.56)$ & $52(15.0)$ & $<.001$ & $<.001$ & .001 \\
\hline Mortality, 3 y, n (\%) & $303(15.0)$ & $277(30.8)$ & $109(51.2)$ & $<.001$ & $<.001$ & $<.001$ \\
\hline Length of stay, hospital, d, median (IQR) & $12.0(8.00-18.00)$ & $15.0(9.00-26.0)$ & $21.0(12.0-39.0)$ & $<.001$ & $<.001$ & $<.001$ \\
\hline Length of stay, intensive care unit, $d$, median (IQR) & $5.00(3.00-7.00)$ & $6.00(4.00-12.0)$ & $10.5(5.00-25.0)$ & $<.001$ & $<.001$ & $<.001$ \\
\hline
\end{tabular}

No anemia (NA): females, hemoglobin (Hb) $\geq 12 \mathrm{~g} / \mathrm{dL} ;$ males, $\mathrm{Hb} \geq 13 \mathrm{~g} / \mathrm{dL}$. Mild anemia (MA): females, $10 \mathrm{~g} / \mathrm{dL}<\mathrm{Hb}<12 \mathrm{~g} / \mathrm{dL} ;$ males, $10 \mathrm{~g} / \mathrm{dL}<\mathrm{Hb}<13 \mathrm{~g} / \mathrm{dL}$. Severe anemia (SA): females and males, $\mathrm{Hb} \leq 10 \mathrm{~g} / \mathrm{dL}$. IQR, Interquartile range; APACHE II, Acute Physiology and Chronic Health Evaluation II; TISS-28, Therapeutic Intervention Scoring System 28. *Conversion factor to SI units, 76.25.

In multivariate regression, mild anemia was associated with an HR of 1.44 (95\% confidence interval [CI], 1.201 to 1.728 ; $P<.001)$ and severe anemia was associated with an $\mathrm{HR}$ of 1.80 (95\% CI, 1.336 to $2.440 ; P<.001$ ) for long-term survival. Intraoperative transfusion, independent of the occurrence of preoperative anemia, was associated with decreased long-term survival (HR, 1.34; 95\% CI, 1.109 to $1.620 ; P=.002$ ). Furthermore, long-term survival was influenced by age, type of surgery, time on $\mathrm{CPB}, \mathrm{ACEF}$ score, $\mathrm{COPD}$, coronary artery disease, diabetes mellitus, atrial fibrillation, and peripheral vascular disease $(P<.05$ for all) (Table 3$)$.

\section{Interaction of Preoperative Anemia Severity and Intraoperative Transfusion}

A significant interaction between preoperative anemia and RBC transfusion was found for long-term survival $(P<.001)$ (Table 4). Nonanemic patients who received an RBC transfusion (HR, 2.127; 95\% CI, 1.754 to 2.579; $P<.001$ ) (Table 5) had approximately the same risk of death during the 3 -year observation period as mildly anemic but nontransfused patients (HR, 2.180; 95\% CI, 1.802 to 2.638; $P<.001$ ) (Table 5). Mildly anemic and transfused patients (HR, 3.057; 95\% CI, 2.588 to $3.610 ; P<.001$ ) 
TABLE 3. Cox regression analysis of factors in 3-year survival

\begin{tabular}{|c|c|c|c|}
\hline & $P$ value & HR & $95 \%$ CI \\
\hline Red blood cell transfusion & .002 & 1.340 & $1.109-1.6$ \\
\hline \multicolumn{4}{|l|}{ Anemia } \\
\hline No anemia & Reference & & \\
\hline Mild anemia & $<.001$ & 1.441 & $1.201-1.7$ \\
\hline Severe anemia & $<.001$ & 1.805 & $1.336-2.4$ \\
\hline Age & $<.001$ & 1.036 & $1.024-1.0$ \\
\hline Male sex & .146 & 1.143 & $0.955-1.3$ \\
\hline Body mass index & .871 & 1.001 & $0.984-1.0$ \\
\hline \multicolumn{4}{|l|}{ Type of surgery } \\
\hline Coronary artery bypass grafting & Reference & & \\
\hline Valves & .001 & 1.569 & $1.196-2.0$ \\
\hline $\begin{array}{l}\text { Coronary artery bypass grafting } \\
\text { and valves }\end{array}$ & .023 & 1.314 & $1.039-1.6$ \\
\hline Cardiopulmonary bypass time & $<.001$ & 1.005 & $1.003-1.0$ \\
\hline \multicolumn{4}{|l|}{ Priority of surgery } \\
\hline Elective & Reference & & \\
\hline Urgent & .079 & 0.754 & $0.550-1.0$ \\
\hline Emergency & .119 & 1.273 & $0.940-1.7$ \\
\hline $\begin{array}{l}\text { Age, creatinine, and ejection } \\
\text { fraction score }\end{array}$ & .025 & 1.373 & $1.040-1.8$ \\
\hline Chronic obstructive pulmonary disease & $<.001$ & 1.779 & $1.485-2.1$ \\
\hline Coronary artery disease & .033 & 1.358 & $1.025-1.7$ \\
\hline Diabetes mellitus & $<.001$ & 1.602 & $1.357-1.8$ \\
\hline Atrial fibrillation & $<.001$ & 1.539 & $1.293-1.8$ \\
\hline Peripheral vascular disease & .003 & 1.344 & $1.103-1.6$ \\
\hline Left ventricular ejection fraction $<35$ & .893 & 1.024 & $0.728-1.4$ \\
\hline Preoperative serum creatinine & .129 & 1.255 & $0.936-1$. \\
\hline
\end{tabular}
$>1.7 \mathrm{mg} / \mathrm{dL}^{*}$

If no reference category is provided, variables are dichotomous (eg, mention of diabetes mellitus vs no mention of diabetes mellitus). $H R$, Hazard ratio; CI, confidence interval. *Conversion factor to SI units, 76.25.

had a risk similar to severely anemic patients without transfusion (HR, 3.350; 95\% CI, 2.230 to 5.031; $P<.001$ ) (Table $5)$. The highest risk of death during the 3 -year observation period was found for severely anemic patients who also required transfusion (HR, 5.098; 95\% CI, 4.087 to 6.359; $P<.001$ ) (Table 5). Long-term survival of patients depending on anemia and/or transfusion is plotted as Kaplan-Meier curves. (An overall comparison regarding all 6 combinations of anemia and transfusion is provided in Figure 2; Kaplan-Meier curves with confidence intervals are shown separately for nontransfused and transfused patients in Figures 3 and 4, respectively.)

\section{DISCUSSION}

The results of our multivariate analysis indicate that the severity of anemia as well as intraoperative transfusion have significant impacts on long-term survival. Regarding the combination of anemia and transfusion, a significant interaction of both factors on survival was seen. Moreover, the outcome effect of severe anemia outweighed that of transfusion. Long-term survival was worse in patients
TABLE 4. Cox regression analysis of factors in 3-year survival, with preoperative anemia and intraoperative transfusion replaced by a product term for characterizing the impact of an interaction between anemia and transfusion on survival

\begin{tabular}{lccc}
\hline \multicolumn{1}{c}{ Factor } & $\boldsymbol{P}$ value & HR & $\mathbf{9 5 \%}$ CI \\
\hline Interaction of anemia and transfusion & $<.001$ & 1.203 & $1.141-1.269$ \\
Age & $<.001$ & 1.035 & $1.024-1.047$ \\
Male sex & .168 & 1.136 & $0.948-1.361$ \\
Body mass index & .849 & 1.002 & $0.984-1.020$ \\
Type of surgery & & & \\
$\quad$ Coronary artery bypass grafting & Reference & 1.000 & \\
$\quad$ Valves & .001 & 1.576 & $1.200-2.070$ \\
$\quad$ Coronary artery bypass grafting & .021 & 1.321 & $1.043-1.672$ \\
$\quad$ and valves & & & \\
Cardiopulmonary bypass time & $<.001$ & 1.005 & $1.003-1.007$ \\
Priority of surgery & & & \\
$\quad$ Elective & Reference & 1.000 & \\
$\quad$ Urgent & .079 & 0.754 & $0.549-1.034$ \\
$\quad$ Emergency & .110 & 1.282 & $0.945-1.738$ \\
Age, creatinine, and ejection & .026 & 1.372 & $1.039-1.812$ \\
$\quad$ fraction score & & & \\
Chronic obstructive pulmonary disease & $<.001$ & 1.783 & $1.489-2.136$ \\
Coronary artery disease & .034 & 1.358 & $1.024-1.803$ \\
Diabetes mellitus & $<.001$ & 1.599 & $1.353-1.889$ \\
Atrial fibrillation & $<.001$ & 1.534 & $1.288-1.828$ \\
Peripheral vascular disease & .003 & 1.351 & $1.108-1.647$ \\
Left ventricular ejection fraction $<35$ & .892 & 1.024 & $0.728-1.440$ \\
Preoperative serum creatinine & .119 & 1.263 & $0.941-1.694$ \\
$\quad>1.7$ mg/dL* & & & \\
\hline
\end{tabular}

If no reference category is provided, variables are dichotomous (eg, mention of diabetes mellitus vs no mention of diabetes mellitus). $H R$, Hazard ratio; $C I$, confidence interval. *Conversion factor to SI units, 76.25.

who presented with anemia and received a transfusion compared with those who did not receive a transfusion.

A large body of evidence supports the view that preoperative anemia adversely influences mortality after cardiac surgery. The adverse effect of mild and severe anemia on outcome was recently reported, confirming that severe preoperative anemia (defined as $\mathrm{Hb}<11 \mathrm{~g} / \mathrm{dL}$ ) was associated with the highest hospital mortality rate. ${ }^{2}$

TABLE 5. Cox regression analysis quantifying the impact of preoperative anemia of different severity and intraoperative transfusion in combination on survival

\begin{tabular}{lccc}
\hline & $\boldsymbol{P}$ value & HR & $\mathbf{9 5} \%$ CI \\
\hline No anemia/no transfusion & Reference & 1.000 & \\
No anemia/transfusion & $<.001$ & 2.127 & $1.754-2.579$ \\
Mild anemia/no transfusion & $<.001$ & 2.180 & $1.802-2.638$ \\
Mild anemia/transfusion & $<.001$ & 3.057 & $2.588-3.610$ \\
Severe anemia/no transfusion & $<.001$ & 3.350 & $2.230-5.031$ \\
Severe anemia/transfusion & $<.001$ & 5.098 & $4.087-6.359$ \\
\hline
\end{tabular}

$H R$, Hazard ratio; $C I$, confidence interval. 

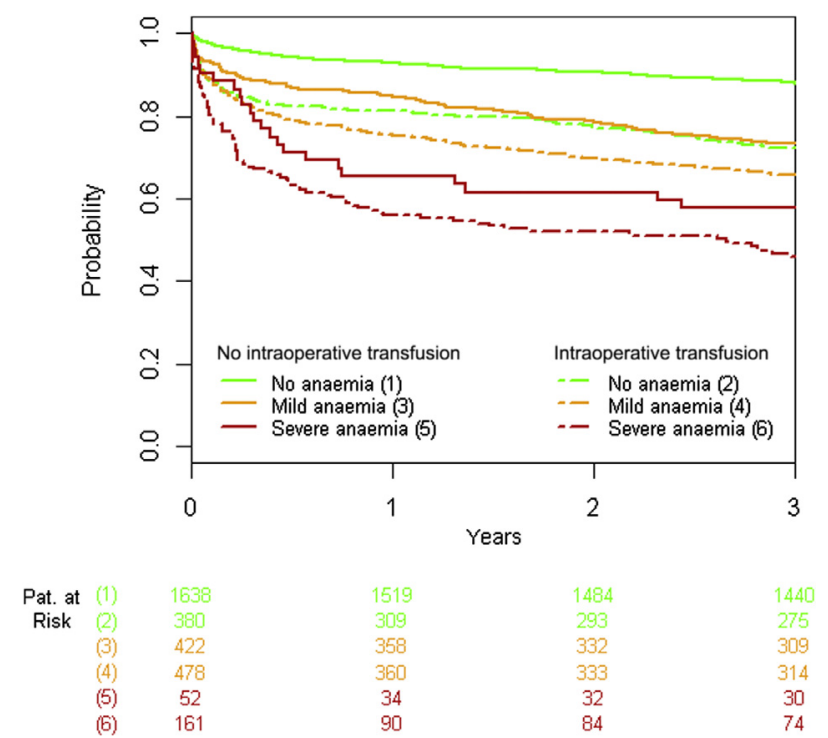

FIGURE 2. Survival analyses. Long-term survival of patients depending on anemia and/or transfusion are illustrated as Kaplan-Meier curves $(P<.001$, log-rank test $) .95 \%$ confidence intervals are shown in Figures 3 and 4. Pat., Patients.

Furthermore, in CABG patients, van Straten et $\mathrm{al}^{3}$ reported higher early mortality when $\mathrm{Hb}$ was 12 to $13 \mathrm{~g} / \mathrm{dL}$ in men and 11 to $12 \mathrm{~g} / \mathrm{dL}$ in women, and higher late mortality when $\mathrm{Hb}$ was $<12 \mathrm{~g} / \mathrm{dL}$ in men and $<11 \mathrm{~g} / \mathrm{dL}$ in women. ${ }^{3}$ For short-term mortality in cardiac surgery, Ranucci et $\mathrm{al}^{23}$ reported significantly higher intraoperative mortality in patients with severe preoperative anemia (defined as a hematocrit $<20 \%$ ) compared with nonanemic patients. In addition, in patients undergoing aortic valve replacement,
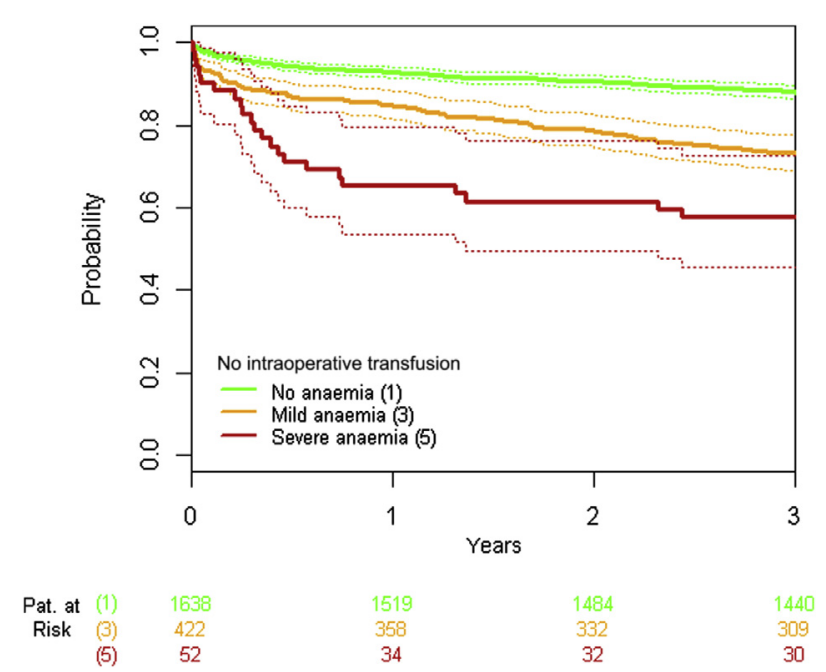

FIGURE 3. Survival analyses. Long-term survival depending on anemia of different severity in patients not requiring intraoperative transfusion are illustrated as Kaplan-Meier curves with corresponding 95\% confidence intervals $(P<.001, \log$-rank test). Pat., Patients.

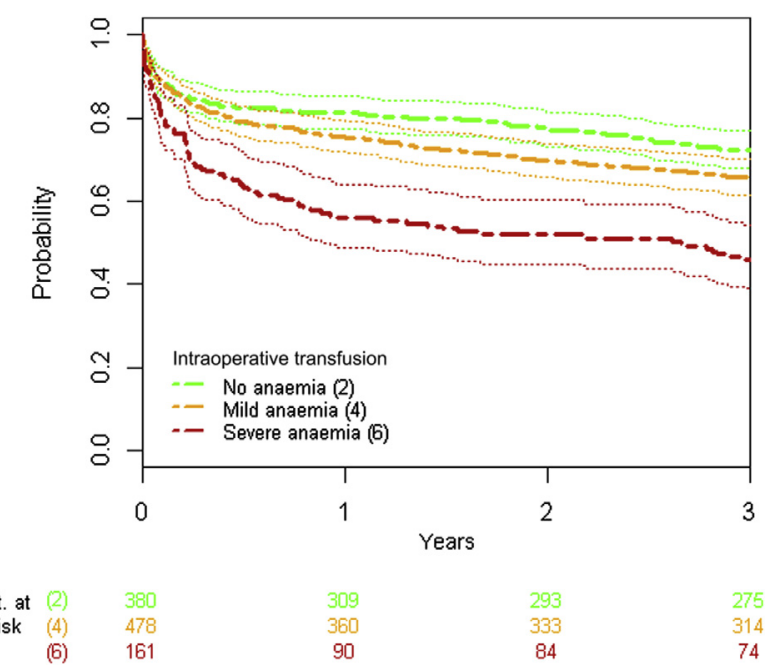

FIGURE 4. Survival analyses. Long-term survival depending on anemia of different severity in patients requiring intraoperative transfusion are illustrated as Kaplan-Meier curves with corresponding 95\% confidence intervals $(P<.001, \log$-rank test). Pat., Patients.

an association of the severity of preoperative anemia with mortality has been reported, albeit for late mortality only. ${ }^{4}$ Although Scrascia et $\mathrm{al}^{2}$ used a different definition of severe anemia than ours, their data and our data underscore the fact that the severity of preoperative anemia has a strong impact on mortality after cardiac surgery. For different types of cardiac surgical procedures, all of these studies demonstrate that the more severe the preoperative anemia, the higher the early or late mortality.

The impact of both, preoperative anemia and transfusion, were studied retrospectively in $922 \mathrm{CABG}$ patients. $^{24}$ The authors reported that only transfused anemic patients had a significantly increased hazard of late mortality compared with nonanemic and nontransfused patients. ${ }^{24}$ In their definition of anemia, using $\mathrm{Hb}<12 \mathrm{~g} / \mathrm{dL}$ in men and $<11 \mathrm{~g} / \mathrm{dL}$ in women, $\mathrm{Hb}$ levels are below the WHO's definition of anemia. Although the patients were stratified for "alive" and "died," and not for "anemic/ nonanemic" or "transfused/nontransfused," their study lacked a nonanemic control group and different severities of preoperative anemia, leaving the impact of anemia and severity of anemia on short- and long-term mortality unclear. $^{24}$ In another retrospective analysis of 16,154 patients focusing on major bleeding in cardiac surgery, ${ }^{13}$ anemia (but not its severity) and transfusion were identified to enhance the deleterious effects of bleeding on operative mortality. Interestingly, the impact of anemia on operative mortality was highest in nontransfused patients who were not affected by major bleeding, resulting in an increase in mortality from $0.7 \%$ to $3.0 \%{ }^{13}$ A recent data analysis investigated patients with on-pump hematocrit values $<25 \%$ and $>25 \%$ and found that the lower hematocrit 
group that underwent transfusion during surgery had a longterm survival (median follow-up of 3.7 years) of $67 \%$, compared with $82 \%$ in the non-transfused group. ${ }^{25}$ The authors concluded that the combined exposure to anemia and $\mathrm{RBC}$ transfusion was associated with decreased long-term survival.

It is well known that the severity of preoperative anemia results in a higher transfusion rate. ${ }^{7}$ On the other hand, transfusion by itself is associated with increased mortality. ${ }^{11}$ It is important to separate effects on outcome, because, for instance, severely anemic patients may be more likely than mildly anemic or nonanemic patients to receive RBC transfusions. Our analysis accounted for this interaction of preoperative anemia and intraoperative transfusion using multivariate analyses. A striking finding of the present study is that whenever preoperative anemia was present, an additional transfusion reduced long-term survival by approximately $50 \%$ (for mild anemia: HR, 2180 to 3057; for severe anemia: HR, 3350 to 5098) (Table 4). Moreover, mildly anemic patients who received a transfusion had the same decrease in long-term survival as severely anemic patients who did not receive a transfusion, with approximately 3-fold lower long-term survival. Thus, the co-occurrence of preoperative anemia and intraoperative transfusion is not always associated with the highest risk of mortality. It depends substantially on the severity of anemia; severe anemia by itself has a greater impact on long-term survival than the combination of mild anemia and transfusion.

Compared with other risk factors, including age, type of surgery, duration of $\mathrm{CPB}$, ACEF score, COPD, coronary artery disease, diabetes mellitus, atrial fibrillation, peripheral vascular disease, and even transfusion, severe anemia was the strongest risk factor. This seems important to us, because preoperative anemia is treatable, although not necessarily by RBC transfusion only, as opposed to the aforementioned risk factors.

The present analysis has several limitations that are important to acknowledge. First, retrospective analysis is subject to usual investigator bias and to errors in manual data extraction from the medical records. Second, our analysis approach did not differentiate between causes of transfusion (ie, surgical cause of bleeding or anemia treatment). Third, we used logistic regression analysis to widely eliminate confounders of comorbidities. Nevertheless, we cannot rule out all potential chronic diseases or comorbidities that may cause preoperative anemia or worsen the outcome. Fourth, we focused on intraoperative transfusion, because it compensates for preoperative and acute hemodilutional anemia. Postoperative transfusion may be considered necessary for other reasons, such as postoperative bleeding or postoperative bone marrow depression. ${ }^{26}$ However, our approach is in line with other reports on preoperative anemia and transfusion ${ }^{25}$ and is strictly focused on the interaction of preoperative anemia and its intraoperative treatment. Fifth, possible confounders, such as preoperative treatment of anemia, ${ }^{27}$ were not available electronically. However, the treatment of preoperative anemia was not part of standard care during the study period, thus limiting a potential bias of our study.

\section{CONCLUSIONS}

Our results suggest that both preoperative anemia and transfusion are by themselves and in combination associated with decreased long-term survival. When anemic patients required transfusion, the risk of death after cardiac surgery may depend to a considerable extent on the severity of preoperative anemia, given that the negative impact of transfusion was multiplied by the underlying severity of preoperative anemia. Finally, the association of preoperative anemia with adverse outcomes may suggest a causal role in cardiac surgery patients. Preoperative anemia could be treated with, for instance, erythropoietin and/or iron in advance to avoid the need for intraoperative transfusion. Intraoperative transfusion to correct preoperative anemia should be handled with caution for this condition.

\section{Conflict of Interest Statement}

C.v.H. received honoraria from Vifor Pharma and Janssen-Cilag and funding unrelated to this work from Bayer AG, Boehringer Ingelheim, Pfizer, Bristol Myers Squibb, Daiichi Sankyo, CSL Behring, Octapharma, Sanofi Aventis and HICC GbR. C.S. received funding unrelated to this study from Abbott, Aspect, Baxter, BBraun, Essex Pharma, Fresenius Kabi, GSK, and Wyeth. M.S. received funding unrelated to this study from Massimo, ratiopharm, Edwards Life Sciences, Pulsion Medical Systems, LMA, Fresenius Medical Care, and LidCO. F.B. received funding unrelated to this work from ClearFlow. L.K., K.S., H.G., and K.W. have nothing to disclose with regard to commercial support.

\section{References} 1. Boening A, Boedeker RH, Scheibelhut C, Rietzschel J, Roth P, Schönburg M.
Anemia before coronary artery bypass surgery as additional risk factor increases
the perioperative risk. Ann Thorac Surg. 2011;92:805-10.
2. Scrascia G, Guida P, Caparrotti SM, Capone G, Contini M, Cassese M, et al.
Incremental value of anemia in cardiac surgical risk prediction with the European
System for Cardiac Operative Risk Evaluation (EuroSCORE) II model. Ann
Thorac Surg. 2014;98:869-75.
3. van Straten AH, Hamad MA, van Zundert AJ, Martens EJ, Schönberger JP, de
Wolf AM. Preoperative hemoglobin level as a predictor of survival after coronary 
artery bypass grafting: a comparison with the matched general population. Circulation. 2009;120:118-25.

4. van Straten AH, Külcü K, Özdemir HI, Elenbaas TW, Soliman Hamad MA. Preoperative hemoglobin level as a predictor of mortality after aortic valve replacement. J Cardiothorac Vasc Anesth. 2013;27:716-22.

5. Kozek-Langenecker SA, Afshari A, Albaladejo P, Santullano CA, De Robertis E, Filipescu DC, et al. Management of severe perioperative bleeding: guidelines from the European Society of Anaesthesiology. Eur J Anaesthesiol. 2013;30: 270-382.

6. Querschnitts-Leitlinien (BÄK) zur Therapie mit Blutkomponenten und Plasmaderivaten. 4: Aktualisierte und überarbeitete Auflage 2014. Available at: http://www. bundesaerztekammer.de/fileadmin/user_upload/downloads/QLL_Haemotherapie_ 2014.pdf. Accessed June 29, 2016.

7. Hung M, Besser M, Sharples LD, Nair SK, Klein AA. The prevalence and association with transfusion, intensive care unit stay and mortality of pre-operative anaemia in a cohort of cardiac surgery patients. Anaesthesia. 2011;66:812-8.

8. Karkouti K, Wijeysundera DN, Beattie WS. Risk associated with preoperative anemia in cardiac surgery: a multicenter cohort study. Circulation. 2008;117: 478-84.

9. Rao SV, Jollis JG, Harrington RA, Granger CB, Newby LK, Armstrong PW, et al. Relationship of blood transfusion and clinical outcomes in patients with acute coronary syndromes. JAMA. 2004;292:1555-62.

10. Murphy GJ, Reeves BC, Rogers CA, Rizvi SI, Culliford L, Angelini GD. Increased mortality, postoperative morbidity, and cost after red blood cell transfusion in patients having cardiac surgery. Circulation. 2007;116: 2544-52.

11. Engoren MC, Habib RH, Zacharias A, Schwann TA, Riordan CJ, Durham SJ. Effect of blood transfusion on long-term survival after cardiac operation. Ann Thorac Surg. 2002;74:1180-6.

12. Karkouti K, Wijeysundera DN, Yau TM, McCluskey SA, Chan CT, Wong PY, et al. Influence of erythrocyte transfusion on the risk of acute kidney injury after cardiac surgery differs in anemic and nonanemic patients. Anesthesiology. 2011; 115:523-30.

13. Ranucci M, Baryshnikova E, Castelvecchio S, Pelissero G. Major bleeding, transfusions, and anemia: the deadly triad of cardiac surgery. Ann Thorac Surg. 2013;96:478-85.

14. Ranucci M, Castelvecchio S, Menicanti L, Frigiola A, Pelissero G. Risk of assessing mortality risk in elective cardiac operations: age, creatinine, ejection fraction, and the law of parsimony. Circulation. 2009;119:3053-61.

15. Knaus WA, Draper EA, Wagner DP, Zimmerman JE. APACHE II: a severity of disease classification system. Crit Care Med. 1985;13:818-29.
16. Cullen DJ, Civetta JM, Briggs BA, Ferrara LC. Therapeutic intervention scoring system: a method for quantitative comparison of patient care. Crit Care Med. 1974;2:57-60.

17. Spies CD, Birnbaum J, Kastrup M, Kerner T, Melzer-Gartzke C, Zielke H. SOPs in Anästhesiologie und Schmerztherapie: alle relevanten Standards und Techniken für die Klinik. Stuttgart: Thieme; 2013.

18. Spies CD, Angstwurm K, Kox WJ, Kastrup M, Melzer-Gartzke C. SOPs in Intensivmedizin und Notfallmedizin: alle relevanten Standards und Techniken für die Klinik. Stuttgart: Thieme; 2013.

19. Carl M, Alms A, Braun J, Dongas A, Erb J, Goetz A, et al. S3 guidelines for intensive care in cardiac surgery patients: hemodynamic monitoring and cardiocirculary system. Ger Med Sci. 2010;8:Doc12.

20. World Health Organization and Centers for Disease Control and Prevention. Worldwide prevalence of anaemia 1993-2005. WHO global database on anaemia. Available at: http://whqlibdoc.who.int/publications/2008/9789241596657_eng. pdf. Accessed January 25, 2015.

21. Glance LG, Dick AW, Mukamel DB, Fleming FJ, Zollo RA, Wissler R, et al. Association between intraoperative blood transfusion and mortality and morbidity in patients undergoing noncardiac surgery. Anesthesiology. 2011; 114:283-92.

22. R Development Core Team; R Foundation for Statistical Computing. R: a language and environment for statistical computing. Available at: http:// www.R-project.org. Accessed June 29, 2016.

23. Ranucci M, Di Dedda U, Castelvecchio S, Menicanti L, Frigiola A, Pelissero G. Impact of preoperative anemia on outcome in adult cardiac surgery: a propensity-matched analysis. Ann Thorac Surg. 2012;94:1134-41.

24. Engoren M, Schwann TA, Habib RH, Neill SN, Vance JL, Likosky DS. The independent effects of anemia and transfusion on mortality after coronary artery bypass. Ann Thorac Surg. 2014;97:514-20.

25. Loor G, Rajeswaran J, Li L, Sabik JF III, Blackstone EH, McCrae KR, et al. The least of 3 evils: exposure to red blood cell transfusion, anemia, or both? J Thorac Cardiovasc Surg. 2013;146:1480-7.e6.

26. Hayden SJ, Albert TJ, Watkins TR, Swenson ER. Anemia in critical illness: insights into etiology, consequences, and management. Am J Respir Crit Care Med. 2012; 185:1049-57.

27. Goodnough LT, Maniatis A, Earnshaw P, Benoni G, Beris P, Bisbe E, et al. Detection, evaluation, and management of preoperative anaemia in the elective orthopaedic surgical patient: NATA guidelines. Br J Anaesth. 2011;106:13-22.

Key Words: preoperative anemia, RBC transfusion, mortality 